\title{
DSC and FT-IR Analysis for the Formulation of Dermal Films with Meloxicam in Bioadhesive Polymeric Matrices
}

\author{
NICOLETA TODORAN ${ }^{1}$, PAULA ANTONOAEA ${ }^{*}$, AURA RUSU ${ }^{1}$, ADRIANA CIURBA ${ }^{1}$, MAGDALENA BIRSAN ${ }^{2}$, EMOKE REDAI ${ }^{1}$ \\ ${ }^{1}$ University of Medicine and Pharmacy of Tirgu Mures, 38 Gheorghe Marinescu Str., Tirgu Mures, 540139, Romania \\ ${ }^{2}$ University of Medicine and Pharmacy Grigore T. Popa Iasi, 16 University Str., Iasi, 700115, Romania
}

\begin{abstract}
The film forming polymers have a primary role in controlling the diffusion of the drug molecules and the bioavailability, its compatibility with the drug being an essential factor of the formulation. This study aimed the thermal analysis by Differential Scanning Calorimetry (DSC) and Fourier Transform Infrared Spectroscopy (FTIR) evaluation of meloxicam associated with HPMC E5, HPMC 15000 and ethylcellulose, in order to identify the compatibility of associations. The results showed that meloxicam has minor interactions in binary or ternary physical mixtures with the three studied polymers, proving that the mixtures are suitable for obtaining bioadhesive matrices by casting and solvent evaporation method.
\end{abstract}

Keywords: meloxicam, ethyl cellulose, infrared, calorimetry

As medicinal form intended for percutaneous use, the dermal films consisting of bioadhesive polymer matrix use relatively simple techniques for preparation [1]. Among their constituents, the film forming polymers (e.g. hydroxypropyl methylcellulose -HPMC, ethyl cellulose -EC, etc. [2,3]) have a primary role in controlling the diffusion of the drug molecules, thus directly determining the bioavailability [4] after the dermal application. Consequently, its compatibility with the drug, and not only, is an essential factor of the formulation [5]. In addition to these two components, skin penetration activators (e.g. Tween 20, propylene glycol, etc [6-8]) are often included in formulations as molecules that have the ability to interact with the structural components of the corneal layer (at the intercorneocytic level by fluidizing and solubilizing the lipid components, or intracorneocytic level by binding to keratin filaments) and cause temporary disturbances in the skin barrier $[6,9]$, thus improving the permeability of the drug [10].

Meloxicam (MX) is chemically 44-hydroxy-2-methyl-N(5-methyl-2-thiazolyl)-2H-1,2-benzothiazine-3-carboxamide1,1-dioxide and belongs to the group of oxicams, being a second-generation NSAID that works by selective blocking of COX-2 [11], water solubility at $25^{\circ} \mathrm{C}$ of $7.15 \mathrm{mg} / \mathrm{L}, \log \mathrm{P}$ 3.43 and pKa 4.08 [12]. The small size of its molecule (<500 Daltons) [13] creates the premise of a possible skin penetration [14] to obtain the anti-inflammatory effect by dermal (local) administration.

The vibrational characteristics in FT-IR spectra are commonly used in formulation studies to determine compatibility with associated components. For example, in 2006, Vijaya Kumar S.G. demonstrated MX compatibility with polyethylene glycol 600 in solid dispersions, identifying characteristic signals for stretching vibrations of $-\mathrm{NH}$ at $3290.3 \mathrm{~cm}^{-1}, \mathrm{C}=\mathrm{N}$ at $1620.1 \mathrm{~cm}^{-1}$ and $\mathrm{S}=0$ at $1153.4 \mathrm{~cm}^{-1}$ [15]. In 2015, Alladi S. demonstrated the compatibility of MX with the excipients proposed for some semi-solid matrices intended for incorporation into hard gelatin capsules. Thus, they detected the characteristic bands for MX at $3291 \mathrm{~cm}^{-1}, 3057 \mathrm{~cm}^{-1}, 2856 \mathrm{~cm}^{-1}, 1626 \mathrm{~cm}^{-1}, 1618 \mathrm{~cm}$ ${ }^{1}, 1065 \mathrm{~cm}^{-1}$ (stretching -OH vibrations, $\mathrm{C}-\mathrm{H}$ aromatic ring, $\mathrm{N}-\mathrm{H}, \mathrm{S}=0$ ) [16]. In another study conducted in 2016, Zaman M. determined the compatibility of MX with HPMC
E15 to prepare oral films, demonstrating the absence of notable interactions between $M X$ and the excipients. The IR spectrum of the MX-HPMC E15 mixture showed the main absorption peaks of MX at: $3285.6 \mathrm{~cm}^{-1}(\mathrm{~N}-\mathrm{H}$ stretching), $1615.8 \mathrm{~cm}^{-1}$ (scissoring vibration of $\left.\mathrm{NH}_{2}\right), 1261.7 \mathrm{~cm}^{-1}(\mathrm{C}-\mathrm{H}$ wagging), $1548.7 \mathrm{~cm}^{-1}$ ( $\mathrm{C}=\mathrm{N}$ stretching), $1149.9 \mathrm{~cm}^{-1}$ ( $\mathrm{S}=0$ stretching) and $710.1 \mathrm{~cm}^{-1}$ (C-H rocking) [17]. The lack interaction of $\mathrm{MX}$ in mixtures with HPMC and EC was also demonstrated in the study conducted in 2010 by Somasundaram $\mathrm{J}$., when the formulation of transdermal patches was proposed [18]. In 2010, Yener G. noticed no interaction between MX and HPMC proposed transdermal film formulations [19].

Our study aims to formulate bioadhesive films for cutaneous use containing $0.1 \%$ MX. Two types of hydroxypropylmethyl cellulose with different viscosities ( $\mathrm{HPMC}_{\mathrm{ES}}$ and $\mathrm{HPMC}_{15000}$ ) were proposed as formers of bioadhesive matrices. A third polymer, ethyl cellulose, was intended as a plasticizer to improve the mechanical properties of the films. The objective at this stage of the study was the DSC and FT-IR spectroscopy evaluation MX compatibility in association with the three chosen polymers.

\section{Experimental part \\ Materials and methods}

Pharmaceutical grade chemicals: Meloxicam (Techno Drugs \& Intermediates Mumbai, India); Hydroxypropyl methylcellulose - HPMC E5 (Methocel E5 - 5 mPaxs, Dow Chemical Midland, USA); Hydroxypropyl methylcellulose HPMC 15000 (Metolose 90 SH - 15000 mPaxs, Shin-Etsu Chemical Tokyo, Japan); Ethyl cellulose - EC 10 (EC 10 mPaxs, Sigma Aldrich Schnelldorf, Germany); Propylene glycol (Scharlau Chemie Barcelona, Spain); Tween 20 (Sigma Aldrich Lyon, France); Chloroform and Absolute ethanol (Chemical Company lasi, Romania); Ultrapure water (Millipore Direct-QS).

Analysed samples: The samples prepared for the analysis were of three types (Table 1): substance (meloxicam - MX, polymer $\mathrm{P}_{1}, \mathrm{P}_{2}$ or $\mathrm{P}_{3}$ ); physical mixture (PM) of polymer(s) with MX, prepared by trituration of mixed powders in a mortar, so as to obtain binary mixture (1:1 w/w) or ternary mixture (1:1:1 w/w); and dermal films (DF) containing MX dispersed 


\begin{tabular}{|c|c|c|c|c|c|c|}
\hline \multirow{2}{*}{ Type } & \multirow{2}{*}{ Code } & \multicolumn{3}{|c|}{ Polymer \% } & \multirow{2}{*}{ MX \% } & \multirow{2}{*}{$\begin{array}{c}\text { Analysis } \\
\text { method }\end{array}$} \\
\hline & & $P_{1}$ & $\mathbf{P}_{2}$ & $\mathbf{P}_{3}$ & & \\
\hline Meloxicam & $\mathrm{MX}$ & - & - & - & 100 & \multirow{4}{*}{$\begin{array}{c}\text { IR } \\
\text { DSC }\end{array}$} \\
\hline HPMC $_{E 5}$ & $\mathrm{P}_{1}$ & 100 & - & - & \multirow{3}{*}{ - } & \\
\hline $\mathrm{HPMC}_{15000}$ & $\mathrm{P}_{2}$ & - & 100 & 100 & & \\
\hline $\mathbf{E C}_{10}$ & $\mathrm{P}_{3}$ & - & - & - & & \\
\hline \multirow{5}{*}{$\begin{array}{c}\text { Physical } \\
\text { mixture (PM) }\end{array}$} & $\mathrm{MX}-\mathrm{P}_{1}$ & 50 & - & - & \multirow{3}{*}{50} & \multirow{5}{*}{$\begin{array}{c}\text { IR } \\
\text { DSC }\end{array}$} \\
\hline & $\mathrm{MX}-\mathrm{P}_{2}$ & - & 50 & - & & \\
\hline & $\mathrm{MX}-\mathrm{P}_{3}$ & - & - & 50 & & \\
\hline & MX-P1-P3 & 33.3 & - & 33.3 & \multirow{2}{*}{33.3} & \\
\hline & $\mathrm{MX}-\mathrm{P}_{2}-\mathrm{P}_{3}$ & - & 33.3 & 33.3 & & \\
\hline \multirow{5}{*}{$\begin{array}{l}\text { Dermal film } \\
\text { (DF) }\end{array}$} & $\mathrm{MX}-\mathrm{P}_{1}$ & $\approx 24$ & - & - & \multirow{5}{*}{$\approx 4$} & \multirow{5}{*}{$\mathrm{DSC}$} \\
\hline & $\mathrm{MX}-\mathrm{P}_{2}$ & - & $\approx 8$ & - & & \\
\hline & $\mathrm{MX}-\mathrm{P}_{3}$ & - & - & $\approx 8$ & & \\
\hline & $\mathrm{MX}-\mathrm{P}_{1}-\mathrm{P}_{3}$ & $\approx 24$ & - & $\approx 8$ & & \\
\hline & $\mathrm{MX}-\mathrm{P}_{2}-\mathrm{P}_{3}$ & - & $\approx 8$ & $\approx 8$ & & \\
\hline
\end{tabular}

Table 1

TYPE AND COMPOSITION OF SAMPLES PROPOSED FOR ANALYSIS

into bioadhesive polymer matrix, prepared bythe castingand solvent evaporation method. Type and composition of samples proposed for analysis are presented in table 1.

\section{Preparation of dermal film samples}

MX $(0.5 \%)$ was dissolved in a mixture $(40 \%)$ of ethanolpropylene glycol (3:1) under continuous stirring for 30 minutes ( 300 rpm; Heidolph RZR1 stirrer, Germany). The aqueous solution of Tween $20(1 \%)$ and then the polymer $\mathrm{P}_{1}(3 \%)$, or $\mathrm{P}_{2}(1 \%)$ was added to the resulting dispersion, under continuous stirring. When appropriate, $P_{2}(1 \%)$ was added at the end, in the form of a chloroform solution. The obtained fluid $(100 \mathrm{~g})$ was kept for $1 \mathrm{~h}$ in an ultrasonic water bath (MRC D80H, London, UK) and then poured into Petri dishes $(5 \times 20 \mathrm{~g})$ from which the solvent was allowed to evaporate [20]. After drying $\left(40{ }^{\circ} \mathrm{C}, 24 \mathrm{~h}\right)$, the formed bioadhesive film $(\approx 2.5 \mathrm{~g} \times 5)$ was cut, weighed and used as a sample to be analysed.

Analysis by IR spectroscopy: The vibrational properties under the action of IR radiation (\% transmittance vs. $\mathrm{cm}^{-1}$ wavenumber) were determined on samples of $1.0 \mathrm{mg}$ compressed with $150 \mathrm{mg} \mathrm{KBr}$, by 8 scans in the spectral

range of 400 to $4000 \mathrm{~cm}^{-1}$, with a resolution of $4 \mathrm{~cm}^{-1}$, using a Thermo Nicolet Avatar 330 FTIR spectrometer controlled by OMNIC 10.1 software.

Thermal analysis by DSC: At each determination, three samples of $5.0 \mathrm{mg}$ (sealed in aluminium crucible of $40 \mu \mathrm{L}$ ) were scanned at a heating rate of $5^{\circ} \mathrm{C} \times \mathrm{min}^{-1}$, in the range of 30 to $300{ }^{\circ} \mathrm{C}$, using a Shimadzu TA-60WS Thermal Analysis Workstation equipped with TA-60 software, recording the heat flux ( $\mathrm{mW}$ ) vs. temperature $\left({ }^{\circ} \mathrm{C}\right)$. The enthalpy $(\Delta \mathrm{H})$ of the obvious thermal transitions (the major peaks in the DSC curves [21]) was calculated by integrating the specific heat at constant pressure $(\mathrm{Cp})$ with respect to the temperature $(\Delta \mathrm{T})$, using the equation: $\Delta \mathrm{H}$ $(\mathrm{J} / g)=C p \times A(A=$ the area under the peak in the DSC curve).

\section{Results and discussions}

Evaluation of MX - polymer(s) association compatibility by comparing the IR spectra is presented in figure 1 .

Nine FT-IR spectra were registered, four of which were spectra of individual substances: meloxicam -MX (a NSAID structurally related to the enolic acid class of 4-hydroxy-

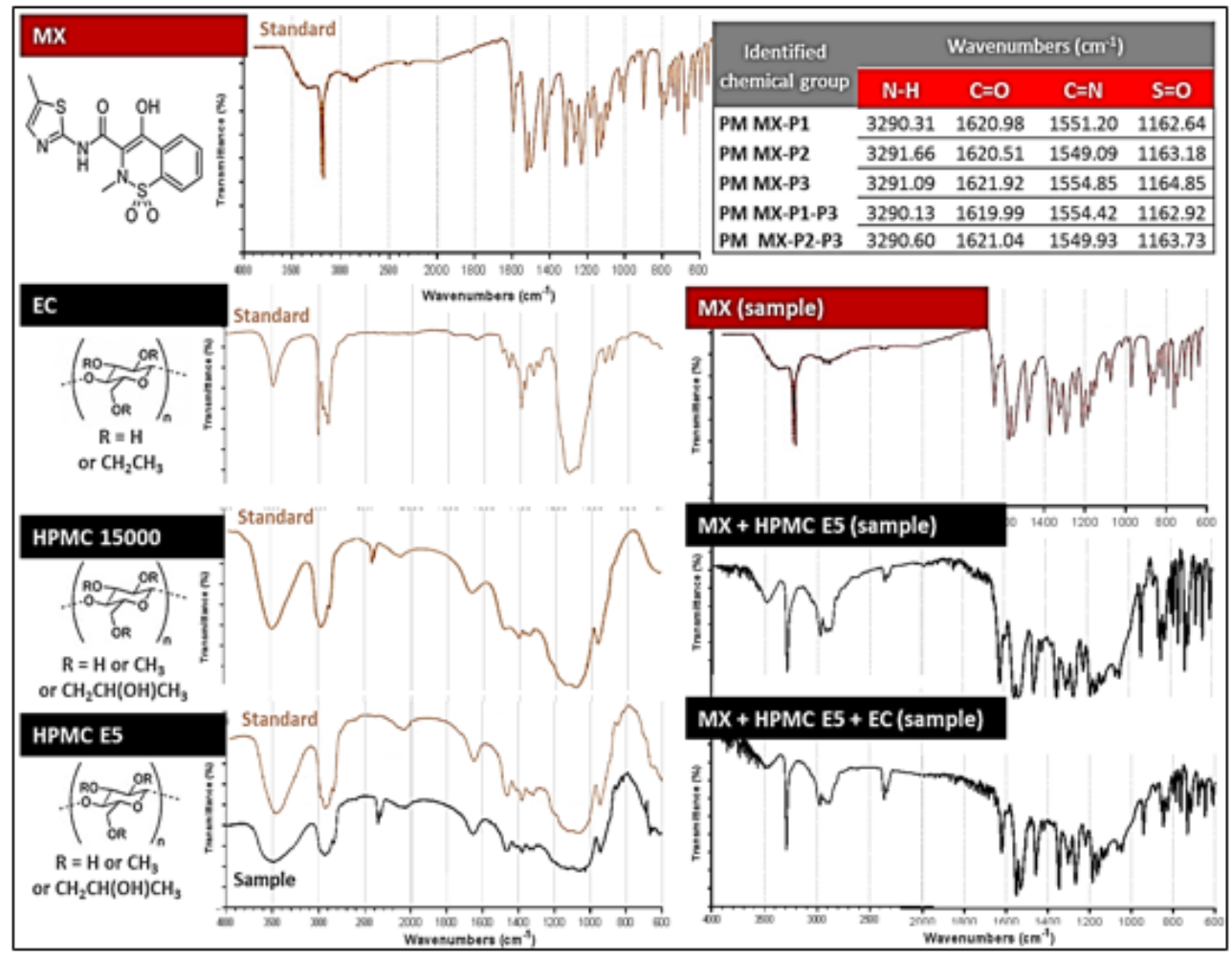

Fig. 1. IR spectra of standards (published data [22]) and of some studied samples: meloxicam (MX) and its physical mixtures $(P M)$ with $\mathrm{HPMC}_{\mathrm{F}}\left(\mathrm{P}_{1}\right)$, $\mathrm{HPMC}_{15000}\left(\mathrm{P}_{2}\right)$ and EC $\mathrm{C}_{10}\left(\mathrm{P}_{3}\right)$ 
1,2-benzothiazine carboxamides) and three were cellulose ether polymers (HPMC ${ }_{65}-\mathrm{P}_{1} ; \mathrm{HPMC}_{15000}-\mathrm{P}_{2} ; \mathrm{EC}_{10}-\mathrm{P}_{3}$ ). These FT-IR spectra (of samples) were compared with reference (standard) spectra published in the literature [22]. The other five FT-IR spectra were determined on the samples prepared in form of physical mixtures (PM) of MX-polymer(s): three binary (MX-P $\left., M X-P_{2}, M X-P_{3}\right)$ and two ternaries (MX-P $\left.-P_{3}, M X-P_{2}-P_{3}\right)$ mixtures.

Spectral properties of meloxicam: Comparing the FT-IR spectra of MX-sample vs. standard, the peaks corresponding to the main functional chemical groups were identified, by assigning their characteristic bands. The most prominent absorption bands found in the MX-sample spectrum were in agreement with the published data: $3289.83 \mathrm{~cm}^{-1}$ (stretching vibrations given by the secondary amine $\mathrm{NH}$ bond), $1621.09 \mathrm{~cm}^{-1}$ (amide bond stretching vibrations of $\mathrm{C}=0)[15,23,24]$ and $1347.06 \mathrm{~cm}^{-1}[23], 1184.9 \mathrm{~cm}^{-1}[24]$, $1162.77 \mathrm{~cm}^{-1}$ [17], $1159.07 \mathrm{~cm}^{-1}, 1153.28 \mathrm{~cm}^{-1}$ and 1149.42 $\mathrm{cm}^{-1}[15]$ (stretching of $\mathrm{S}=0$ bond).

Although the molecular fingerprint area (1500-400 $\mathrm{cm}^{-1}$ ) was more difficult to interpret, it was still possible to identify other MX characteristic bands: at peak frequencies of $1540.92 \mathrm{~cm}^{-1}(\mathrm{C}=\mathrm{N}$ binding tensile vibrations) [17], $1457.69 \mathrm{~cm}^{-1}$ (deformation vibrations for $\mathrm{CH}$ ) [24], 1452.21 $\mathrm{cm}^{-1}$ (deformation vibrations for $\mathrm{C}=\mathrm{C}$ of the aromatic ring) [23], $1131.87 \mathrm{~cm}^{-1}$ and $1194.34 \mathrm{~cm}^{-1}$ (for the $-\mathrm{OH}$ group) [24], $1044.56 \mathrm{~cm}^{-1}$ (deformation vibrations within the $\mathrm{CH}$ binding plane of the aromatic ring) and 856.17-645.14 $\mathrm{cm}^{-1}$ (deformation vibrations outside the $\mathrm{CH}$ binding plane from the aromatic ring) [25].

Spectral properties of physical mixtures: The FT-IR spectra of PM samples show that the frequencies of the characteristic groups of $M X(N-H, C=O, C=N, S=0)$ remained unchanged.

In the FT-IR spectrum of MX-P, the characteristic bands of $\mathrm{HPMC}_{\mathrm{F5}}$ (3396.43 $\mathrm{cm}^{-1}$ - tensile vibration given by $-\mathrm{OH}$; $2902.73 \mathrm{~cm}^{-1}, 1598.4 \mathrm{~cm}^{-1}$ and $1045.16 \mathrm{~cm}^{-1}$ - tensile vibration given by the $\mathrm{CH}$ link) were also been identified and were found consistent with other recent data from the literature $[26,27]$. In the case of MX-P there were no changes in the main frequencies of $M X$ spectrum, which indicates the lack of MX-polymer interaction [17]. In MX$\mathrm{P}_{3}$ spectrum, some characteristic frequencies for $\mathrm{EC}_{10}$ appeared (3487.95 $\mathrm{cm}^{-1}$ and $3291.09 \mathrm{~cm}^{-1}$ - tensile vibrations given by $-\mathrm{OH} ; 2977.7 \mathrm{~cm}^{-1}$ and $2876.04 \mathrm{~cm}^{-1}$ - for tensile vibrations which occur due to the $\mathrm{CH}$ bond), these data being similar to those from the literature $[22,28]$. As expected, in the case of ternary mixtures (MX-P $-\mathrm{P}_{2}$ and MX-P $\left.-P_{3}\right)$, the frequencies of the characteristic groups of both $M X^{3}$ and polymers of the mixture were found to be similar with literature other data previously published $[17,22,28]$.

The spectral differences found when comparing the FTIR spectra of the studied physical mixture samples with those of the single substances could be attributed to possible physical interactions caused by continuous rubbing or grinding of the powders due to the trituration which can powder more strongly than other mixing methods [21]. This assumption is also supported on published data which reveals the lack of any interaction of MX with such polymers, the occurrence of some additional peaks being attributed to the polymers, rather than considering them as undesirable interactions $[18,29,30]$.

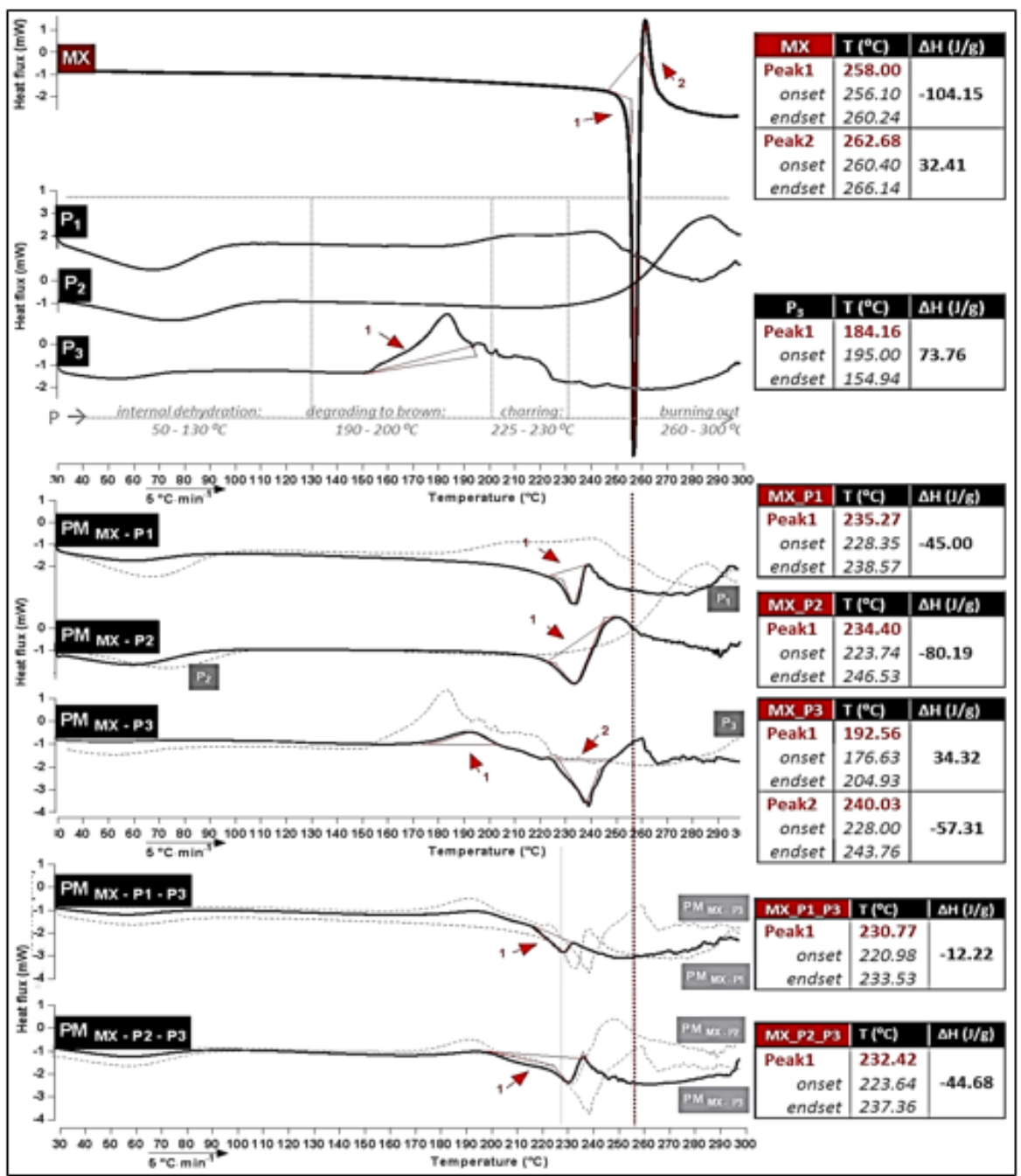

Fig. 2. DSC curves of the studied powder samples: meloxicam $(\mathrm{MX})$ and its physical mixtures (PM) with $\mathrm{HPMC}_{\mathrm{E5}}\left(\mathrm{P}_{1}\right), \mathrm{HPMC}_{15000}\left(\mathrm{P}_{2}\right)$ and $\mathrm{EC}_{10}\left(\mathrm{P}_{3}\right)$ 
Evaluation of MX -polymer(s) association compatibility by comparing the DSC curves is presented in figure 2.

The DSC thermal curves were determined by increasing the temperature by $5^{\circ} \mathrm{C} / \mathrm{min}$ in the range of $30^{\circ} \mathrm{C}$ to $300^{\circ} \mathrm{C}$, conditions established on the basis of published data which show that both the structural changes of meloxicam and the studied polymers can be highlighted under these conditions, the results obtained being also in agreement with these data [19,31,32].

\section{Thermal properties of meloxicam}

According to the literature, $\mathrm{MX}$ melts at $254{ }^{\circ} \mathrm{C}$ with decomposition [32]. The DSC curve of MX sample shows an endothermic peak at $258{ }^{\circ} \mathrm{C}(\Delta \mathrm{H}=-104.15 \mathrm{~J} / \mathrm{g})$ corresponding to the melting point, very nearly followed by an exothermic peak at $262.68{ }^{\circ} \mathrm{C}$, suggesting that the substance melts with decomposition. The determined melting temperature indicates that $\mathrm{MX}$ sample has a purity of $98.43 \%$, which is accepted for a pharmaceutical grade. It also appears that the substance has a crystalline structure, the shape of the peak being deep and narrow, showing that the temperature remains constant during melting.

\section{Thermal properties of polymers}

As a rule, observed thermal events for cellulose derivatives often describe degradation processes and, to a lesser extent, melt processes. So that, they generally degrade to brown at $90-200{ }^{\circ} \mathrm{C}$, carbonate at $225-230^{\circ} \mathrm{C}$ and reach the complete degradation at $260-300^{\circ} \mathrm{C}[12,33]$.

The determined DSC curves show that $P_{1}$ and $P_{2}$ polymers exhibit a similar thermal behaviour with a wide endothermic peak in the range of 50 to $100^{\circ} \mathrm{C}$, which, according to literature [12,33], corresponds to the loss of water released from the $-\mathrm{OH}$ groups of the lateral ether chains through an internal dehydration. Carbonization and burning occur slowly for $P_{1}$ (from $190-200{ }^{\circ} \mathrm{C}$ ), while $P_{2}$ carbonizes and breaks down more abruptly (at temperatures above $240-250^{\circ} \mathrm{C}$ ). Dehydration is much less evident in $\mathrm{P}_{3}$, while decomposition occurs early and quite suddenly, resulting in the appearance of a well-balanced exothermic peak at approximately $184^{\circ} \mathrm{C}$ which, according to published data $[33,34]$, corresponds to the decomposition of the polymer.

\section{Thermal properties of physical mixtures}

The similarity of PM-samples thermograms indicates that substances retain their properties in a mixture, even if the curves do not overlap completely. Differences in the thermal behaviour of MX in the studied physical mixtures can be attributed to interactions between components; however, they do not indicate incompatibilities between the components of the mixture [35]. A possible incompatibility may be indicated by the emergence of new peaks or the disappearance of the peak which indicates the melting point of the active drug [33,36]. Areas where deviations of the DSC curves occur suggest that $M X$ is the one that changes some of its properties in mixtures with the polymers used. In the thermal curve of MX, the deep and narrow endothermic peak of the melting temperature $\left(258{ }^{\circ} \mathrm{C}\right.$ with an enthalpy change of $-104.15 \mathrm{~J} / \mathrm{g}$ ) can be considered a characteristic of MX (in crystalline form) and is thus useful for the evaluation of the MX structure of the physical mixtures with the polymers selected in the study.

An overall comparison shows that the thermal curves of the PM-samples (binary or ternary) show a displacement

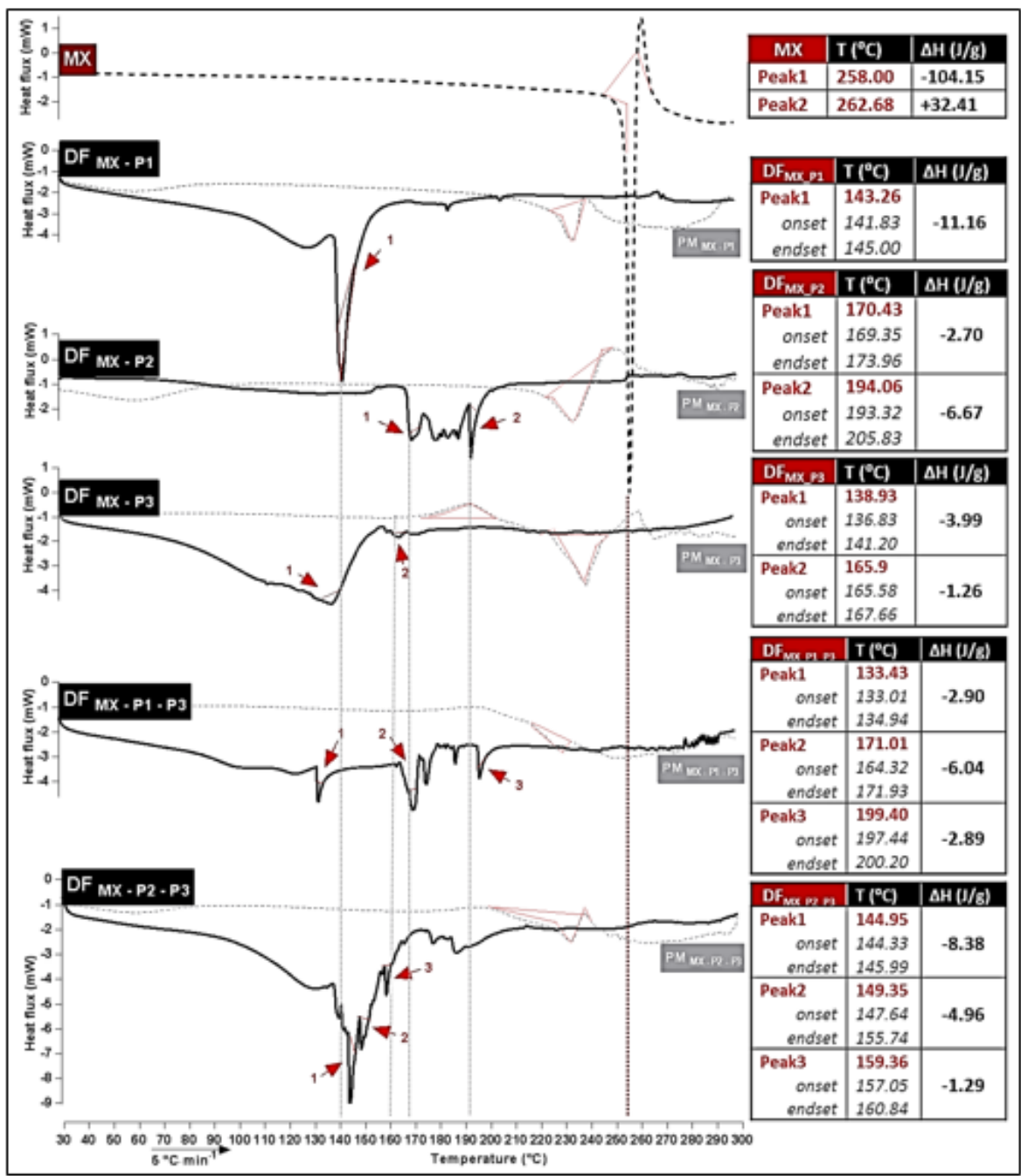

REV.CHIM.(Bucharest) 69 No. $12 \downarrow 2018$
Fig. 3. DSC curves of meloxicam (MX) dermal film samples prepared in form of polymeric matrices of $\mathrm{HPMC}_{E 5}\left(\mathrm{P}_{1}\right)$, $\operatorname{HPMC}_{15000}\left(P_{2}\right), \mathrm{EC}_{10}\left(\mathrm{P}_{3}\right)$, or combinations 
of approximately $20^{\circ} \mathrm{C}$ of the endothermic peaks, as MX melting at $230-240^{\circ} \mathrm{C}$. In these thermograms, the form of the peaks is much wider, which shows that MX melting occurs this time in a temperature range, such behaviour being generally specific to amorphous structures that initially soften and become a viscous paste and then, at a higher temperature, they become liquids of low viscosity [37]. As a result, the observed changes could be attributed to the amorphous state of MX in the mixtures, possibly resulting from advanced pulverization of crystals during sample preparation.

Analysing groups of binary mixtures versus ternary mixtures, we found that the melting point of MX was modified by $4-5^{\circ} \mathrm{C}$ in the mixture with one of the polymers (binary PM), and with approximately $10^{\circ} \mathrm{C}$ in the mixture with two polymers (ternary PM). Also, there was a lower amplitude of peaks that characterizes the MX specific thermal events when it is in binary mixtures but also less expressed in ternary mixtures. These differences can be attributed to the different mass ratio between the components ( $1 / 2 \mathrm{MX}$ in binary mixtures, $1 / 3$ in the ternary mixtures, as compared to MX as an individual substance), and to the nature of the polymer(s) in the mixture.

When comparing enthalpy changes (DH) in areas indicating $M X$ melting in physical mixtures (PM), it was noted that the intensity of the endothermic process was influenced by the nature of the polymer and decreased in the order: MX-P $(-80 \mathrm{~J} / \mathrm{g})>$ MX-P $(-57 \mathrm{~J} / \mathrm{g})>\mathrm{MX}-\mathrm{P}_{1}(-45$ $\mathrm{J} / \mathrm{g})$, and $M X-P_{-}-P_{3}(-45 \mathrm{~J} / \mathrm{g})>M X^{3}-P_{1}-P_{3}(-12 \mathrm{~J} / \mathrm{g})$. Starting from the assumption that a DH value as close to $-104.15 \mathrm{~J} /$ $\mathrm{g}(\Delta \mathrm{H}$ determined during the MX-sample melting) denotes reduced interactions of $M X$ in the mixture, and considering the $\Delta H$ value as a measure of the interactions determined by the type of the polymer in the mixture, it can be concluded that the influence determined by the nature of the polymer (its inertia) decreases in the case of binary mixtures in the following order: $P_{2}\left(\right.$ HPMC $_{15000}$ hydroxylated polymer with high viscosity, high degree of polymerization and low percentage of -OH groups in the composition [33,38]) $>\mathrm{P}_{2}\left(\mathrm{EC}_{10}\right.$ - unhydroxylated polymer at side chains $[33,38])>P_{3}^{2}\left(H_{P M C}\right.$ - hydroxylated polymer with low viscosity, low degree of polymerization and high percentage of $-\mathrm{OH}$ groups in the composition $[33,38])$. In the case of ternary mixtures, $\mathrm{EC}_{10}$ determines more reduced interactions with $M X$ when mixed with $\mathrm{HPMC}_{15000}\left(\mathrm{P}_{2}-\mathrm{P}_{3}\right)$ as opposed to the mixture with $\mathrm{HPMC}_{\mathrm{E} 5}$ $\left(\mathrm{P}_{1}-\mathrm{P}_{3}\right)^{15000}$

Evaluation of MX - dermal film(s) matrix by analysing and comparing the DSC curves is presented in figure 3 .

Dermal films were formulated so as to obtain MX polymer matrices in the form of thin films but resistant to retain their shape when handled. Considering the formulation for dermal administration and the behavioural particularities observed in the process of the casting and solvent evaporation method when preparing DF products, it was necessary to use different concentrations of the three selected polymers (according to Table 1) and the addition of auxiliaries (Tween 20 and propylene glycol) which remain in the end products. Thus, five products were obtained: three films constituted of a single-polymer matrix (DF-P) and two films constituted of combinations of two polymers (DF-P-P).

The thermograms obtained in the DSC analysis of these DF products show the disappearance of peaks which were obviously characteristic of MX and the three polymers used in both the substance samples and the physical mixture samples. Also, different thermal behaviours were observed in the five DF samples, which is why the major differences found cannot be attributed to the auxiliaries present in the films as they were used in the same concentrations. Instead, these differences can be attributed to the method of DF-sample preparation and could be explained by MX dispersions of varying degrees formed in the mass of films by recrystallization of MX during the formation of the polymer matrix by evaporation of ethanol [39], a volatile solvent used as intermedium to ensure the homogeneity of dispersion $[40,41]$. The nature of phenomena that cause the peaks in thermogram is difficult to identify and interpret. In the absence of other determined or available data, it can be inferred that the film that seems more stable (cohesive) is the one prepared with HPMC ${ }_{15000}\left(\mathrm{MX}_{\mathrm{X}} \mathrm{P}_{2}\right)$. The addition of $E C_{10}\left(M X-P_{2}-P_{3}\right)$ determines the relaxation of this structure, an effect that could positively influence the mechanical properties of the dermal film (this polymer stabilizing such compositions [42, 43]).

According to the Nnamani P.O. specifications (2013), a reduction in enatal pia may suggest a minimization of the recrystallization of the active drug, but also a nonhomogeneity of the matrix composition [44]. In agreement with Yener G. (2010), the recrystallization process was avoided due to propylene glycol in their proposed compositions. [19] Also, the deviation of the peaks characteristic of the active drug may indicate the conversion of the crystalline substances into the amorphous form, which may suggest a satisfactory dispersion of these in the polymeric matrices and, subsequently, a favoured release $[16,17,44]$.

\section{Conclusions}

Meloxicam has minor interactions with HPMC E5, HPMC 15000 and EC 10, maintaining its vibrational characteristics by FT-IR analysis of binary or ternary physical mixtures, the polymers proving to be suitable for formulating matrices in form of bioadhesive films. The matrices obtained by casting and solvent evaporation method have thermal behaviours, when scanning by DSC, that include phase transitions which can be associated with melting or dissolving and low crystallization phenomena, without major interactions.

Acknowledgments: The determinations were performed in the Multidisciplinary Laboratory of University of Medicine and Pharmacy of Tirgu Mures. The study was funded by the University of Medicine and Pharmacy of Tirgu Mures Research Grand number 275.6.11.01.2017.

\section{References}

1.THAKUR, V.K., THAKUR, M.K., Handbook of polymers for pharmaceutical technology Scrivener Publishing LLC, USA, 2, 2015, p. 38.

2.KANDAVILLI, S., NAIR, V., PANCHAGNULA, R., Pharm. Technol., 26, nr. 5, 2002, p. 62.

3.BANERJEE, S., CHATTOPADHYAY, P., GHOSH, A., DATTA, P., VEER V., Int. J. Adhes. Adhes., 50, 2014, p. 70.

4.ALLADI, S., SHASTRI, N.R., Arch. Pharm. Res., 38, 2015, p. 801.

5.GAIKWAD, A., J. Pharm. Sci., 1, no. 1, 2013, p. 1.

6.SARPOTDAR, P.P., ZATZ, J.L., J. Pharm. Sci., 75, 1986, p. 176.

7.SARPOTDAR, R., ZATZ, J.L., Drug. Dev. Ind. Pharm., 12, 1986, p. 1625.

8.SUTA, L.M., TUDOR, A., SANDULOVICI, C.R., STELEA, L., HADARUGA, D., MIRCIOIU, C., BALINT, G.S., Rev. Chim. (Bucharest), 68, no. 4, 2017, p. 726.

9.PANDEY, A., MITTAL, A., CHAUHAN, N., ALAM, S., J. Mol. Pharm. Org. Process. Res., 2, 2014, p. 113.

10.AL HUSSEIN, S.M., TODORAN, N., IMRE, S., AL HUSSEIN, H., ZAERA, A.M, AL HUSSEIN, H., DOGARU, M.T., Rev. Chim. (Bucharest), 68, no. 5, 2017, p. 937. 
11.MARINESCU, G., CULITA, D.C., PATRON, L., NITA, S., MARUTESCU, L., STANICA, N., OPREA, O., Rev. Chim. (Bucharest), 65, no. 4, 2014, p. 426.

12.SWEETMAN, S.C., Martindale - The complete drug references, 36, Pharmaceutical Press, London, UK, 2009, p. 80, 2143.

13.MACIELAG, M.J., Chemical properties of antimicrobials and their uniqueness, Antibiotic discovery and development, Springer NY, DOUGHERTY, T.J ., PUCCI, M.J., USA, 2012, p. 795.

14.YADAV, V., IJPSR, 3, no. 2, 2012, 376.

15.VIJ AYA KUMAR, S.G., MISHRA, D.N., Yakugaku Zasshi, 126, no. 8, 2006, 657.

16.ALLADI, S., SHASTRI, N.R., Arch. Pharm. Res., 38, 2015, 801.

17.ZAMAN, M., HANIF, M., QAISER, A.A., Acta Pol. Pharm. Drug Res., 73, no. 5, 2016, p. 1351.

18.SOMASUNDARAM, J., SUNDARAPANDIAN, R., POSINA, A., MUTHUMANICKAM, A., MOHAMED, T.S.S., MADHUSUDHANA, C.C., Malay. J. Pharm. Sci., 8, no. 2, 2010, 25.

19.YENER, G., UNER, M., GONULLU, U., YILDIRIM, S., KILIC, P., SAGLIK, S.S., BARLA, A., Chem. Pharm. Bull., 58, no. 11, 2010, p. 1466.

20.ANTONOAEA, P., TODORAN, N., RÉDAl, E., CIURBA, A., BOGDAN, C., MOLDOVAN, M., MUNTEAN, D.L., Acta Med. Maris., 63, no. 2, 2017, p. 56.

21.PANI, N.R., NATH, L.K., ACHARYA, S., BHUNIYA, B., J. Therm. Anal. Calorim., 108, 2012, p. 219.

22.DIBBERN, H.W., MÜLLER, R.M, UV and IR Spectra, Pharmaceutical Substances (UV and IR) and Pharmaceutical and Cosmetic Excipients, Cantor Verlag, WIRBITZKI, E., Aulendorf, Germany, 2002, p. 835, 1507, $1653,1655$.

23.ELBARY, A.A., ALI, A.A., ABOUD, H.M., Bull. Fac. Pharm. Cairo Univ., 50, 2012, p. 89.

24.SHAKHTSHNEIDER, T.P., MYZ, S.A., DYAKONOVA, M.A., BOLDYREV, V.V., BOLDYREVA, E.V., NIZOVSKII, A.I., KALINKIN, A.V., KUMAR, R., Acta Phys. Pol. A., 120, no. 2, 2011, p. 272.

25.COATES, J., Interpretation of infrared spectra, A Practical Approach in Encyclopedia of Analytical Chemistry, J ohn Wiley \& Sons Ltd, MEYERS, R.A., Chichester, .2000, p. 10815.

26.ZAINI, E., FITRIANI, L., EFFENDY, S., NOVIZA, D., HALIM, A., Orient J. Chem., 33, no. 2, 2017.
27.ABDELBARY, A., BENDAS, E.R., RAMADAN, A.A., MOSTAFA, D.A., AAPS Pharm. Sci. Tech., 15, no. 6, 2014, p. 1603.

28.SUTHAR, V., PRATAP, A., RAVAL, H., Bull. Mater. Sci., 23, 2000, p. 215.

29.SHIRSAND, S.B., LADHANE, G.M., PRATHAP, S., PRAKASH, P.V., RGUHS J. Pharm. Sci., 2, no. 4, 2012, p. 58.

30.ALLADI, S., SHASTRI, N.R., Arch Pharm. Res., 38, 2015, p. 801.

31.LI, T., REN, C., WANG, M., ZHAO, L., WANG, X., FANG, L., AJPS, 2, no. 6, 2007, p. 249.

32.SUTU, L.M., VLAIA, L., FULIA, A., LEDETI, I., HADARUGA, D., MIRCIOIU, C., Rev. Chim. (Bucharest), 64, no. 11, 2013, p. 1279.

33.THAKUR, V.K., THAKUR, M.K., Handbook of polymers for pharmaceutical technology, vol. 3, Biodegradable polymers, 3, Scrivener Publishing LLC, USA, 2015, p. 136, 230.

34.LAI, H.L,, PITT, K., CRAIG, D.Q., Int. J. Pharm., 386, no. 1-2, 2010, p. 178.

35.BHARATE, S.S., BHARATE, B.S., BAJAJ , N.A., J. Excipients and Food Chem., 1, no. 3, 2010, p. 3.

36.LATE, S.G., BANGA, A.K., Pharmazie, 63, no. 6, 2008, p. 453.

37.MUHAMMAD, Z., MUHAMMAD, H., ASIF ALI, Q., Acta Pol. Pharma., 73, no.5, 2016, p. 1351.

38.OCHIUZ, L., LISA, G., GRIGORAS, C., AVADANEI, M., GAFITANU, E., Mat. Plast. (Bucharest), 2008, 45, no. 4, p. 373.

39.PATTNAIKA, S., SWAINA, K., MALLICK, S., LINC, Z., I. J. Pharm., 406, 2011, p. 106.

40.GUNGOR, S., ERDAL, S.M., OZSOY, Y., Plasticizers in transdermal drug delivery systems, in Recent Advances in Plasticizers, InTech Open Access, LUQMAN, M., Rijeka, Croatia, 2012, p. 91.

41.BIRSAN, M., BIBIRE, N., VIERIU, M., PANAINTE, A.D., COJOCARU, I., Rev. Chim. (Bucharest), 68, no. 10, 2017, p. 2349.

42.TEODORRESCU, M., HLEVCA, C., COSMA, C., STEFANESCU, M., BUMBAC, C., IONESCU, I., Rev. Chim. (Bucharest), 64, no. 1, 2013, p. 95.

43.SNEJ DROVA, E., DITTRICH, M., Pharmaceutically used plasticizer, in Recent Advances in Plasticizers, InTech Open Access, LUQMAN, M., Rijeka, Croatia, 2012, p. 45.

44.NNAMANI, P.O., KENECHUKWU, F.C., DIBUA, E.U., OGBONNA, C.C., MOMOH, M.A., OLISEMEKA, A.U., OBUMNEME, A.C., ATTAMA, A.A., Sci. Res. Essays., 8, no. 22, 2013, p. 973.

Manuscript received: 30.02 .2018 